Published in final edited form as:

ACS Synth Biol. 2017 March 17; 6(3): 428-438. doi:10.1021/acssynbio.5b00299.

\title{
The Impact of Chromatin Dynamics on Cas9-Mediated Genome Editing in Human Cells
}

\author{
René M. Daer ${ }^{*}$, Josh P. Cutts, David A. Brafman, and Karmella A. Haynes \\ School of Biological and Health Systems Engineering, Arizona State University, 501 E. Tyler Mall, \\ ECG 344A, Tempe, Arizona 85287, United States
}

\begin{abstract}
In order to efficiently edit eukaryotic genomes, it is critical to test the impact of chromatin dynamics on CRISPR/Cas9 function and develop strategies to adapt the system to eukaryotic contexts. So far, research has extensively characterized the relationship between the CRISPR endonuclease Cas9 and the composition of the RNA-DNA duplex that mediates the system's precision. Evidence suggests that chromatin modifications and DNA packaging can block eukaryotic genome editing by custom-built DNA endonucleases like Cas9; however, the underlying mechanism of Cas9 inhibition is unclear. Here, we demonstrate that closed, genesilencing-associated chromatin is a mechanism for the interference of Cas9-mediated DNA editing. Our assays use a transgenic cell line with a drug-inducible switch to control chromatin states (open and closed) at a single genomic locus. We show that closed chromatin inhibits binding and editing at specific target sites and that artificial reversal of the silenced state restores editing efficiency. These results provide new insights to improve Cas9-mediated editing in human and other mammalian cells.
\end{abstract}

\section{Graphical Abstract}

\footnotetext{
*Corresponding Author, rene.daer@asu.edu. ASSOCIATED CONTENT Supporting Information

The Supporting Information is available free of charge on the ACS Publications website at DOI: 10.1021/acssynbio.5b00299. Annotated sequences of the plasmids used in this study are available online (https://benchling.com/hayneslab/f_/V1mVw1Lpchromatincrispr-interference/). Plasmids have been deposited in the DNASU repository and are available under accession codes UnSC00746685 (http://dnasu.org/DNASU/GetCloneDetail.do?cloneid=746685) and UnSC00746686 (http://dnasu.org/DNASU/ GetCloneDetail.do?cloneid=746686).

Supplementary Figure S1, ChIP data for dCas9/sg034; Supplementary Table S1, List of sgRNAs; Supplementary Table S2, List of primers for nested PCR of genomic DNA from Cas9/sgRNA treated samples; Supplementary Table S3, List of primers with their sequences (PDF)

Author Contributions

RMD performed DNA construction, cell culturing and assays, and SURVEYOR assay. The clone library was generated by KAH and sequenced by DNASU. RMD and JPC performed ChIP assays. All authors analyzed the data and composed the figures and text.

The authors declare no competing financial interest.
} 


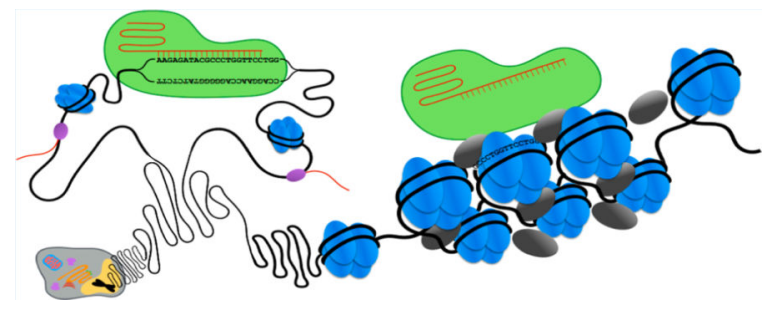

\section{Keywords}

Cas9-mediated editing; chromatin; INDEL

Extensive characterization and engineering is driving the CRISPR/Cas9 system to the forefront of biomedical research, human gene therapy, and tissue regeneration. ${ }^{1-4}$ Realizing the full potential of CRISPR/Cas9 editing in eukaryotic cells will require efficient access to target sites within chromatin, the ubiquitous DNA-protein complexes that organize eukaryotic genomes, regulate gene expression, and render DNA less accessible to nucleases. ${ }^{5-7}$ While some evidence suggests that chromatin modifications and DNA packaging can block eukaryotic genome editing by custom-built DNA endonucleases, ${ }^{8-12}$ the underlying mechanism of Cas9 interference is unknown. Here, we present direct evidence that closed, gene-silencing-associated chromatin inhibits Cas9-mediated DNA editing. These results establish closed chromatin as a target for improving CRISPR/Cas9 efficiency in human and other eukaryotic cells.

There is conflicting evidence on whether chromatin interferes with Cas9 binding and nuclease activity in human cells. Chromatin immunoprecipitation (ChIP) mapping of dCas9, which lacks nuclease activity, showed preferential binding at off-target sites across the human genome with characteristics of open chromatin: high levels of DNasehypersensitivity and protein-coding gene sequences. ${ }^{8,13,14}$ Wu et al. (2014) reported reduced DNA cleavage at off-target sites near closed chromatin versus on-target sites near open chromatin. ${ }^{8}$ While Cas9-mediated editing is not completely blocked at the silenced SERPINB5 locus, which contains methylated DNA, the reported editing frequency was only $\$ 8 \% .^{9}$ Taken together, these data suggest Cas9 may be inhibited by closed chromatin.

However, Chen et al. (2016) showed that pericentromeric heterochromatin inhibited INDEL formation. ${ }^{12}$ Perez-Pinera et al. (2013) found that dCas9-based activators were functional at sites within closed chromatin, suggesting binding was not prevented. ${ }^{15}$ So far, no study has compared Cas 9 activity and binding at a single site for both open and polycomb-mediated closed chromatin.

\section{RESULTS AND DISCUSSION}

Here, we use a model silencing system developed in Hansen et al. $(2008)^{16}$ to control the chromatin state at a single site, a stably integrated firefly luciferase transgene. We directly measured the impact of closed chromatin on Cas9-mediated DNA editing by targeting Cas9 to sites within the luciferase gene in unsilenced, partially silenced, and fully silenced chromatin states. The Gal4EED HEK293 cell line contains a doxycycline (dox)-inducible 
transgene that expresses Gal4EED, which binds upstream of luciferase and recruits endogenous Polycomb Repressive Complexes (PRCs), key regulators of facultatively closed chromatin ${ }^{17}$ (Figure 1a, see Methods for detail). PRCs target hundreds of genes and play a critical role in gene silencing, embryonic development, stem cell maintenance and differentiation, and tumor suppression, ${ }^{18-22}$ and thus, understanding whether differences in PRC accumulation influence Cas9 activity is necessary for advancing biomedical applications.

GAL4EED cells grown with $1 \mu \mathrm{g} / \mathrm{mL}$ dox for $96 \mathrm{~h}$ show maximal levels of repression (Figure 1b). We observed that the GAL4EED cell line shows less luciferase expression than the parental Luc14 cell line, which lacks the Gal4EED transgene, perhaps due to leaky Gal4EED expression and a partially silenced chromatin state (Figure 1c). The chromatin states in GAL4EED are stable over time and in the presence of transfected plasmids. Once initiated by Gal4EED, the silenced state remains stable up to $96 \mathrm{~h}$ after dox is removed and Gal4EED expression is no longer activated. ${ }^{16}$ In our previous work, we showed that control plasmids that express fluorescent proteins do not alter the expression levels of active or Gal4EED-silenced luciferase. ${ }^{23}$

We constructed a series of plasmids expressing Cas9 and a short guide RNA (sgRNA) designed to target 1 of 23 sites within Gal4UAS-TK-luciferase. Editing efficiencies were determined using a SURVEYOR digestion assay and a Bioanalyzer (Figure 2a). The target sites are distributed across 900 basepairs (bp) of the transgene located downstream of the Gal4EED binding site (5xGal4UAS in Figure $2 b$ ). The sgRNAs showed a wide variability of INDEL frequency from zero (below detection limits) to almost $40 \%$ in Luc14 cells (Figure 2c).

To determine the effect of facultative closed chromatin on Cas9-mediated editing, we compared the editing efficiencies of Cas9 in cells where the luciferase target was set to different expression states: unsilenced (Luc14), partially silenced (GAL4EED), and fully silenced (GAL4EED + dox) (Figure 1c). For this analysis, we used the five sgRNAs that showed the highest editing efficiencies in preliminary tests (Figure 2c) in Luc14 cells: sg034, sg031, sg025, sg044, and sg048. We also tested four additional sgRNAs, located farther upstream ( $\mathrm{sg} 046, \mathrm{sg} 055, \mathrm{sg} 032, \mathrm{sg} 054)$ in order to investigate Cas9 interference closer to the initiation site of chromatin compaction. In order to control for varying transfection and expression levels across cell lines and conditions, we added an enhanced green fluorescent protein (EGFP) reporter gene to the Cas9 plasmid (Figure 3a). In this plasmid, EGFP expression is driven by the same promoter as Cas9, but the T2A signal allows EGFP to be translated as a separate peptide to avoid interference with Cas9 function. We used the percentage of GFP-positive cells (Figure 3b) to normalize editing efficiency values across different experiments.

Cas9-mediated editing was reduced at target sites in fully silenced chromatin compared to unsilenced chromatin for six of the nine sgRNAs we tested (Figure 3c). The greatest significant reductions occurred within $150 \mathrm{bp}$ of the transcription start site downstream of the chromatin initiation site at $5 \times \mathrm{xGal} 4$ at sites $\operatorname{sg} 046(p=0.002), \operatorname{sg} 055(p=0.092), \operatorname{sg} 032(p$ $=0.008)$, and $\operatorname{sg} 054(p=0.001)$. In the unsilenced state (Luc14), average editing efficiencies 
at these sites were 7.5 to $55.1 \%$ while mutation frequencies were below detection limits in both the partially (GAL4EED) and fully (GAL4EED + dox) silenced states. These results suggests that editing at TSS-proximal sites is sensitive to closed chromatin. Cas9-mediated editing in fully silenced chromatin was reduced, but not completely inhibited, farther downstream at $\operatorname{sg} 034(p=0.024)$ and $\operatorname{sg} 044(p=0.022)$ compared to unsilenced chromatin. Interestingly, editing efficiency at sg025, located between sg031 and sg044, and sg048, located downstream of g044, is not decreased in the presence of closed chromatin. This suggests that interference may occur in a Cas9/sgRNA-dependent manner or that the spreading of closed chromatin from the UAS is discontinuous. Overall, our results reveal differences in Cas9 accessibility at a greater resolution than what has been reported to date for a single genomic locus. Furthermore, comparison of open, moderately closed, and fully closed states at several on-target sites along a single locus allowed us to detect different levels of interference that are the direct outcome of the formation of facultative chromatin.

Next, we tested the hypothesis that in addition to reducing editing efficiency, silenced chromatin also affects the types of mutations that are generated at the target site. We analyzed mutations at target site sg034 because at this location the closed state still showed detectable Cas9-mediated editing. Sequencing of cloned mutants from Cas9-edited DNA confirmed lower editing efficiency at a target site in fully silenced chromatin compared to unsilenced chromatin. We then compared the distribution of mutated sequences from unsilenced- and fully silenced-chromatin samples. We detected various mutations that were generated in the absence of a repair template by nonhomologous end joining (NHEJ) at target site sg034. These mutations primarily consisted of deletions ranging from 1 to $24 \mathrm{bp}$ (Figure 4a). A small number of insertions (1 to $205 \mathrm{bp}$ ) and single base pair substitutions were also detected. DNA cloned from Cas9/sg034-treated luciferase in the unsilenced chromatin state showed a higher frequency and broader range of affected nucleotides compared to the fully silenced chromatin state (Figure $4 \mathrm{~b}$ ). The most frequent mutation was a single base pair deletion at the Cas9 cut site in both the unsilenced and fully silenced chromatin states ( $12.3 \%$ and $2.3 \%$, respectively). This result led us to reject our hypothesis. The mutant library sequence data indicate that Cas9-mediated editing is reduced by $\sim 30 \%$ in fully silenced chromatin. SURVEYOR assays showed a similar reduction, $\sim 40 \%$. Therefore, the sequencing data and the SURVEYOR data provide corroborating evidence that repressive chromatin interferes with Cas9-mediated editing at site sg034.

In order to investigate inducible chromatin and Cas9 binding, we performed chromatin immunoprecipitation followed by quantitative PCR (ChIP-qPCR) (Figure 5a). First, we used an anti-H3K27me3 antibody to map the silencing mark at luciferase. H3K27me3 is required for the maintenance of Polycomb-mediated chromatin compaction. We detected 29- to 338fold increases in mean $\mathrm{H} 3 \mathrm{~K} 27 \mathrm{me} 3$ enrichment at luciferase in GAL4EED cells that were treated with dox for $96 \mathrm{~h}$ compared to untreated Luc14 cells. We also detected 4- to 93-fold increases in $\mathrm{H} 3 \mathrm{~K} 27 \mathrm{me} 3$ enrichment spanning the Cas9/ sgRNA target sites in untreated GAL4EED cells relative to Luc14 cells. These data, along with the Luciferase expression assays in Figure 1b, validate the dox-induced, facultative silenced chromatin at luciferase. Previous work by Hansen et al. showed through ChIP-qPCR that upon addition of dox, Polycomb Group 2 (PRC2) protein EZH2, Polycomb Group 1 (PRC1) protein CBX8, and the H3K27me3 mark accumulate at the luciferase transgene in GAL4EED cells. ${ }^{16}$ We can 
conclude from their data that when Gal4EED protein binds upstream of luciferase, PRC2 is recruited and trimethylates $\mathrm{H} 3 \mathrm{~K} 27$. $\mathrm{H} 3 \mathrm{~K} 27 \mathrm{me} 3$ binds PRC1, which is associated with nucleosome compaction and gene silencing.

Next, we used ChIP-qPCR to investigate whether interference of Cas9 activity is associated with a decrease in Cas9 binding. We used deactivated Cas9 (dCas9), which lacks DNAcutting activity, ${ }^{24}$ tagged with a C-terminal FLAG sequence to analyze the binding activity of the Cas9/sgRNA complex at unsilenced, partially silenced, and fully silenced chromatin. Formaldehyde-cross-linked chromatin was extracted from dCas9/sgRNA-transfected cells and sheared to $\sim 700 \mathrm{bp}$. ChIP was carried out in triplicate using an antibody against the FLAG tag. We observed a 3- to 5-fold decrease in mean dCas9 enrichment at sg032 in cells with partial or full silencing at luciferase compared to the unsilenced state (Figure 5c). This result and the changes in editing efficiency we observed at sg032 (Figure 3c) support a mechanism where closed chromatin blocks access of Cas9/sgRNA complexes to the target site. In order to further investigate how Cas9 binding is associated editing efficiency, we investigated two sites where editing was either partially affected or unaffected by the closed chromatin state. $\mathrm{Sg} 034$ showed comparable editing in the unsilenced and partially silenced states (Figure 3c). The ChIP-qPCR results show comparable enrichment of dCas9 in these two states for $\mathrm{sg} 034$. In the fully silenced state where editing efficiency was reduced at $\operatorname{sg} 034$, dCas9 enrichment was undetectable. $\mathrm{Sg} 031$ showed the least amount of interference (Figure 3c). We detected very modest decreases in the mean editing efficiencies for the partially and fully silenced state compared to the unsilenced state. The ChIP-qPCR data followed a similar trend, where dCas9 enrichment was reduced but not eliminated. Perhaps at this site, modest levels of Cas9 binding are sufficient to allow DNA editing. In summary, these results strongly suggest that closed chromatin reduces editing efficiency by blocking access of Cas9 to the target site.

Next, we investigated whether changes in chromatin states (illustrated in Figure 6a) could enhance or restore Cas9-mediated editing. In order to induce a hyperactive expression state, we transfected Luc14 cells with a plasmid that expressed the strong transcriptional-activator Gal4-p65. We exposed the luciferase transgene to Cas9 editing by cotransfecting these cells with the Cas9/sg034 plasmid. Gal4-p65 induced luciferase expression approximately 6-fold compared to the basal expression level in Luc14 cells (Figure 6b). SURVEYOR showed reduced INDEL formation at hyperactivated luciferase compared to the basal level ( $p=$ 0.018), suggesting that dynamic chromatin remodeling through transcriptional activation or competition with transcription factors interferes with Cas9-mediated INDEL formation. Next, we investigated Cas 9 efficiency after restoring the active state from a previously silenced state. GAL4EED + dox cells were treated with anti-SuZ12 siRNA to disrupt PRC2 accumulation, or Gal4-p65 to enhance luciferase expression. SuZ12, a member of the PRC2 complex, is required for maintaining the H3K27me3 mark. ${ }^{16}$ Anti-SuZ12 stimulated partial reactivation compared to the basal expression state and showed full recovery of Cas9 editing efficiency compared to the fully silenced state $(p=0.045)$ (Figure 6b and c). Gal4-p65treated GAL4EED + dox cells showed full reactivation of luciferase compared to the basal expression level and partially restored the frequency of INDEL formation (Figure $6 \mathrm{~b}$ and c). These results suggest that artificial restoration of gene expression is an effective approach for enhancing Cas9-mediated editing at a target gene. 
In conclusion, our results provide direct evidence that at a single genomic locus, Polycombmediated chromatin structure impairs Cas9-mediated DNA editing and Cas9 binding at specific sites. Specifically, in the partially and fully repressed chromatin states, the sg032 target site is less accessible to dCas9/sgRNA binding and INDEL formation is reduced. Similarly, at the fully repressed chromatin state, the sg034 target site is less accessible to dCas9/sgRNA binding and INDEL formation is also reduced. Others have investigated the Cas9/sgRNA-target binding step using dCas 9 and found off-target binding to be reduced at sites of closed chromatin. $8,13,14$ In vitro studies suggest that the nucleosome core particle directly contributes to Cas9 interference. Nuclease activity on naked DNA confirmed that Cas9/sgRNA is active in vitro. ${ }^{25}$ Experiments that used reconstituted chromatin templates demonstrated that nucleosome-occupied regions are blocked from Cas 9 binding. ${ }^{26,27}$ Our data support these previous observations by demonstrating that closed chromatin inhibits Cas9/sgRNA-DNA binding at an on-target site. Reduced enrichment of Cas9 is associated with reduced INDEL formation. Taken together, our findings support a mechanism for Cas9 inhibition where chromatin compaction and nucleosome occupancy disrupt Cas9-mediated editing by blocking accessibility of the target site.

Our findings identify repressive chromatin as a critical barrier to efficient Cas9-mediated editing in mammalian cells. In high-throughput applications, such as generating knockout libraries for model organisms, many target sites may be located in closed chromatin in certain cell types. Many sgRNAs may be prone to high failure rates; thus, trial-and-error to achieve gene editing may be impractical. Methods for opening closed chromatin, such as transcriptional activators ${ }^{28}$ and inhibitors of hetero-chromatin proteins ${ }^{29,30}$ might enhance Cas9 editing efficiency. We observed that treating cells with siRNA against the silencing protein SuZ12 led to full recovery of editing efficiency comparable to the basal expression state (Figure 6). Inducing an active state with a transactivator (Gal4p65) might inhibit Cas9 via competition with the activator and the transcription complex. Therefore, an effective general strategy for restoring an open, Cas9-accessible state at chromatin-regulated target sites may be siRNA-mediated inhibition of closed chromatin. Our study with a switchable Polycomb chromatin system ${ }^{16}$ sheds light on the impact of eukaryotic chromatin on Cas9mediated genome editing and opens new avenues to for enhancing Cas9 function in the context of the human genome.

\section{METHODS}

\section{Plasmid DNA Construction}

In order to determine transfection efficiencies using flow cytometry, we modified the vectors pX330-U6-Chimeric_BB-CBh-hSpCas $9^{4}$ (a gift from Feng Zhang, Addgene plasmid \#42230) and pX330A_d-Cas9-1 × 4 [Nakagawa 2015] (a gift from Takashi Yamamoto, Addgene plasmid \#63598) using the T2A peptide skipping sequence to express EGFP from the same mRNA transcript as the Cas9 protein. PX330 or pX330A and the gBlock Gene Fragment (Integrative DNA Technologies) FseI-NLS-T2A-EGFP-EcoRI containing EGFP were cut with FseI (New England BioLabs) and FastDigest EcoRI (ThermoFisher Scientific) and ligated using T4 DNA Ligase (New England BioLabs). We named this new vector pU6(BbsI)_CBh-Cas9-T2A-EGFP (DNASU UnSC00746685). SgRNAs used in the study 
(Supplementary Table S1) were designed using the CRISPR design tool at crispr.mit.edu. ${ }^{9}$ DNA oligos were synthesized with the overhangs for cloning into pX330g or pX330g_dCas9 (Integrative DNA Technology). Drop-in of sgRNAs followed the cloning protocol described in Cong et aA . 2013. The Gal4-p65 fusion was expressed from plasmid CMV-Gal4p65_MV1 (DNASU UnSC00746686). Annotated sequences of the plasmids used in this study are available online (https://benchling.com/hayneslab/f_/V1mVw1Lpchromatin-crispr-interference/).

\section{Cell Culturing and Transfections}

The Luc14 cell line carries a firefly luciferase gene (Gal4UAS-TK-luciferase), which is stably integrated into the genome of HEK293 cells. A second cell line, GAL4EED, contains the firefly luciferase gene (Gal4UAS-TK-luciferase) as well as a TetO-CMV-Gal4EED transgene, which carries a Gal4 DNA-binding motif (Gal4) fused to an embryonic ectoderm development (EED) open reading frame driven by TetO-CMV promoter. ${ }^{15}$ Expression of the Gal4EED fusion protein-encoding sequence is silenced by a Tetracycline repressor (TetR) (Figure 1a). The cell line also contains a puromycin (puro)-inducible anti-Gal4EED miRNA to counter leaky transcription of TetO-CMV-Gal4EED. The removal of puro and addition of doxycycline (dox) to cultured GAL4EED cells releases the TetR protein from TetO-CMVGal4EED and allows the expression of Gal4EED. Gal4EED binds to the Gal4UAS site and switches the chromatin state at luciferase from active to silenced through accumulation of PRC (Figure 1B, Hansen et al., 2008, ${ }^{16}$ and Haynes et al., 201123).

Cells were grown in Gibco DMEM high glucose 1× (Life Technologies) with $10 \%$ Tet-free Fetal Bovine Serum (FBS) (Omega Scientific), $0.5 \mu \mathrm{g} / \mathrm{mL}$ puro and $1 \%$ penicillin streptomycin (ATCC) at $37{ }^{\circ} \mathrm{C}$ in a humidified $5 \% \mathrm{CO}_{2}$ incubator. At time $0 \mathrm{~h}$, puromycin was removed and GAL4EED cells were induced with doxycyclin (dox) (Santa Cruz Biotechnology) at $1 \mu \mathrm{g} / \mathrm{mL}$. At $72 \mathrm{~h}$, Luc14 cells and dox-induced GAL4EED cells were seeded in 12-well plates such that at $96 \mathrm{~h}$, cells reached $90 \%$ confluency. One well from each cell type was collected for Luciferase assay (see below). The remaining wells were used for lipid-mediated transfection. For pX330g/sgRNA transfections, $0.5 \mu \mathrm{g}$ plasmid was used/well, $3 \mu \mathrm{L}$ Lipofectamine LTX, and $1 \mu \mathrm{L}$ Plus Reagent (Life Technologies) per manufacturer's protocol. For $\mathrm{pX} 330 \mathrm{~g} / \mathrm{sgRNA}$ transfections, $0.5 \mu \mathrm{g}$ plasmid was used/well, 3 $\mu \mathrm{L}$ Lipofectamine LTX, and $1 \mu \mathrm{L}$ Plus Reagent (Life Technologies) per manufacturer's protocol. At $144 \mathrm{~h}$, cells were collected to determine transfection efficiency by flow cytometry and editing efficiency by SURVEYOR Assay (see below).

For p65 CMV-Gal4p65_MV1 transfections, $0.5 \mu \mathrm{g}$ of each plasmid was used/well, $3 \mu \mathrm{L}$ Lipofectamine LTX, and $1 \mu \mathrm{L}$ Plus Reagent (Life Technologies) per manufacturer's protocol. At $144 \mathrm{~h}$, cells were collected for downstream analyses, including determining transfection efficiency, and performing Luciferase Assay and SURVEYOR Assay (described below).

\section{Luciferase Assay}

Cells were washed with $0.5 \mathrm{~mL}$ PBS (Irvine Scientific), detached with $0.2 \mathrm{~mL}$ trypsin (Life Technologies), collected with the addition of $0.5 \mathrm{~mL}$ DMEM, and spun at $100 \mathrm{RCF}$. 
Supernatant was aspirated and the cell pellet was resuspended in $2 \mathrm{~mL}$ of FACS buffer (PBS with $1 \%$ FBS) and filtered using $35 \mu \mathrm{m}$ cell strainers (Electron Microscopy Sciences). Twenty $\mu \mathrm{L}$ of cells + FACS buffer were counted and gated using the BD Accuri C6 Flow Cytometer and software (BD Biosciences). The luciferase assay was performed using Steady-Luc Firefly HTS Assay Kit (Biotium) according to manufacturer's protocol. Briefly, $100 \mu \mathrm{L}$ of cells in FACS buffer from each sample were added to three wells of a Corning and Costar 96-well Cell Culture Plate, black, clear bottom (Bioexpress). One hundred $\mu \mathrm{L}$ of Luciferase working solution was added to each well. Three wells with FACS buffer (without cells) plus Luciferase working solution were read and the highest measured value of the three wells was used as background signal. The plate was incubated for 5 min with orbital shaking and luminescence was read using a Synergy H1Multi-Mode Reader (Biotek). Luciferase expression per cell was calculated as follows: Sample Luciferase per cell $=$ [Sample Luciferase signal] - background signal/[cell count $\times(100 \mu \mathrm{L} / 20 \mu \mathrm{L})]$.

\section{SURVEYOR Assay}

Genomic DNA was extracted using a QIAamp DNA Mini Kit (Qiagen). Cas9/sgRNA target DNA was amplified using Phusion polymerase first with external primers P197 5' gctcactcattaggcacccc and P198 5' -ggcgttggtcgcttccggat. PCR products were diluted 1:1000 in water. Nested PCR was performed using primers flanking the Cas9/sgRNA target site (Supplementary Tables S2 and S3). An annotated map of primers is available online (UASTK-luc HEK293, https://benchling.com/hayneslab/f_/V1mVw1Lp-chromatin-crisprinterference/). PCR products were purified (GenElute PCR Clean-Up, Sigma) and SURVEYOR assay (IDT) was performed according to the manufacturer's protocol. Briefly, $400 \mathrm{ng}$ of PCR product was mixed with $1.5 \mu \mathrm{L}$ of annealing buffer $(10 \mathrm{mM}$ Tris- $\mathrm{HCl}(\mathrm{pH}$ $8.8), 1.5 \mathrm{mM} \mathrm{MgCl} 2$, and $50 \mathrm{mM} \mathrm{KCl}$ ), and brought to $15 \mu \mathrm{L}$ with water. PCR products were melted and reannealed and digested with $1 \mu \mathrm{L}$ SURVEYOR enzyme and $1 \mu \mathrm{L}$ Enhancer for $1 \mathrm{~h}$ at $42{ }^{\circ} \mathrm{C}$. The concentrations of fragments in each sample were measured on an Agilent 2100 Bioanalyzer. The ratio of uncut wildtype (WT) to cut heteroduplex DNA fragments $\left(\mathrm{HD}_{\text {large }}, \mathrm{HD}_{\text {small }}\right)$ was calculated as follows: Percent editing efficiency $=100 \times$ $\left[\mathrm{HD}_{\text {large }}+\mathrm{HD}_{\text {small }}\right] /\left[\mathrm{HD}_{\text {large }}+\mathrm{HD}_{\text {small }}+\mathrm{WT}\right]$.

Genomic DNA from untreated Luc14 and GAL4EED cells and genomic DNA from Cas9/ sgRNA treated cells lacking Snuclease treatment were used as controls to distinguish background noise from actual cut heteroduplex DNA fragments.

The editing efficiencies shown in Figures 3 and 6 were normalized by transfection efficiency. At $72 \mathrm{~h}$ post-transfection (12-well plates, $\sim 0.4 \times 10^{6}$ cells/well), cells were washed with $0.5 \mathrm{~mL}$ PBS (Irvine Scientific), detached with $0.2 \mathrm{~mL}$ trypsin (Life Technologies), collected with $0.5 \mathrm{~mL}$ DMEM, and spun at $100 \mathrm{~g}$ for $5 \mathrm{~min}$. Supernatant was aspirated and the cell pellet was resuspended in $2 \mathrm{~mL}$ of FACS buffer (1\% FBS in $1 \times$ PBS) and filtered using $35 \mu \mathrm{m}$ cell strainers (Electron Microscopy Sciences). Live cells were gated based on forward and side scatter using the BD Accuri C6 Flow Cytometer and software (BD Biosciences). Data was analyzed using FlowJo software. Fluorescence intensity for ten thousand live cells, detected with settings for GFP (488 nm laser, 533/30 filters), was plotted against cell count. The GFP-expression threshold was determined using non-GFP expressing 
HEK293 cells. Transfection efficiency was calculated as the percent of cells GFP-positive cells in the total live cell population. This value was used to normalize editing efficiencies to cells containing the Cas9/sgRNA plasmid: Percent editing efficiency normalized to transfection efficiency $=[$ Percent editing efficiency $] /[$ transfection efficiency $]$.

Statistical Analyses-For analyses of SURVEYOR Assay data, standard deviations were calculated for $n=3$ biological replicates. The differences of means for Luc14/GAL4EED cells and Luc14/GAL4EED + dox cells were calculated using the two sample, one-tailed Student's $t$ test with a confidence of $97.5 \%$ for 2 degrees of freedom and a test statistic of $t_{(0.025,2)}=4.303$.

\section{Mutant Clone Library}

The sg034 target region was PCR amplified from genomic DNA and prepared as described above (see "SURVEYOR assay"). Thirty ng ( 0.072 pmols) of each blunt $\sim 630$ bp PCR product was ligated with linear pJET1.2 vector $(0.05$ pmol ends) in a $10 \mu \mathrm{L}$ reaction following the manufacturer's protocol (CloneJET PCR Cloning Kit, Life Technologies) with the following modifications: $1 \times$ ligation buffer (Roche), T4 DNA ligase (New England Biolabs). Reactions were incubated at room temperature $\left(25^{\circ} \mathrm{C}\right)$ for $5 \mathrm{~min}$, mixed with 50 $\mu \mathrm{L}$ of thawed Turbo competent DH5-alpha E. coli (New England Biolabs), and incubated on ice for $5 \mathrm{~min}$. Transformed cells were plated directly on prewarmed LB agar $(100 \mu \mathrm{g} / \mathrm{mL}$ ampicillin) and incubated overnight at $37{ }^{\circ} \mathrm{C}$ to grow colonies. Liquid cultures ( $200 \mu \mathrm{L} \mathrm{LB}$ broth, $100 \mu \mathrm{g} / \mathrm{mL}$ ampicillin) were inoculated in deep round-bottom 96-well plates with single colonies collected via sterile, disposable pipet tips. Plasmid DNA was purified using the Montage Plasmid Miniprep HTS 96 Kit (Millipore). Sanger sequencing was performed using primer P163 (5'-caaaccccgcccagcgtctt). The sequence data were aligned to the pUASTK-luc reference sequence in Benchling using MAFFT. ${ }^{31}$ Sequence variants were binned manually and counted using Excel software.

\section{Cross-Linked Chromatin Immunoprecipitation (ChIP)}

Luc14, GAL4EED, and GAL4EED + dox cells were electroporated with plasmid pX330g_dCas9/sg031, pX330g_dCas9/sg032, or pX330g_dCas9/sg034 using the Neon Transfection System (Invitrogen) following manufacturers protocols. Electroporation settings were as follows: $100 \mu \mathrm{L}$ tip, Pulse voltage $1100 \mathrm{~V}$, pulse width $20 \mathrm{~ms}, 2$ pulses, with cell density $5 \times 10^{7}$ cells $/ \mathrm{mL}$. Two transfections were plated into each $15 \mathrm{~cm}$ plates for each cell type. Transfected cells were grown at $37^{\circ} \mathrm{C}$ for $72 \mathrm{~h}$ before collection for IPs.

Transfected (for dCas9 IPs) and nontransfected (for H3K27me3 IPs) were collected by trypsin-treatment, and incubated with $20 \mathrm{~mL}$ of $1 \%$ formaldehyde (Thermo Fisher Scientific) $/ 1 \times$ Dulbecco's PBS for 10 min at room temperature. Cross-linking was quenched with $125 \mathrm{mM}$ glycine for $5 \mathrm{~min}$. Cross-linked cells were washed twice with cold $1 \times$ PBS buffer + Pierce Protease Inhibitors (Thermo Fisher Scientific) for 5 min with shaking. Cells were washed again with $1 \times$ PBS buffer + Pierce Protease Inhibitors without shaking. Cells were spun at $1000 \mathrm{rpm}$ for $5 \mathrm{~min}$ between each wash step. To lyse cells, $70 \mu \mathrm{L}$ of crosslinked cells were resuspended in $112.5 \mu \mathrm{L}$ of Cell Lysis Buffer [10 mM Tris pH 8.0 (ThermoFisher), $10 \mathrm{mM} \mathrm{NaCl}, 0.2 \%$ IGEPAL (Sigma)] plus Protease Inhibitors and 
incubated on ice $10 \mathrm{~min}$. Lysed cells were spun for $5 \mathrm{~min}$ at $2500 \mathrm{rpm}$. Nuclei were resuspended and lysed in $1 \mathrm{~mL}$ of Nuclei Lysis Buffer [1\% sodium dodecyl sulfate (SDS) (Sigma), $10 \mathrm{mM}$ ethylenediaminetetracacetic acid (EDTA) (Fisher Scientific), $50 \mathrm{mM}$ Tris$\mathrm{HCl} \mathrm{pH} 8.1$ (Sigma)] plus Protease Inhibitors and incubated on ice for $10 \mathrm{~min}$. Lysed nuclei were diluted with $0.5 \mathrm{~mL}$ of ChIP Dilution Buffer [1\% Triton X-100 (Santa Cruz Biotech), 2 mM EDTA, $150 \mathrm{mM} \mathrm{NaCl}$ (Sigma), $20 \mathrm{mM}$ Tris-HCl, pH. 8.0] and split into five $300 \mu \mathrm{L}-$ aliquots. Cells were disrupted using a Qsonica Q700A Sonicator with a 5.5" Cup Horn. Sonicated chromatin was spun at $\sim 10000 \mathrm{~g}$ for $10 \mathrm{~min}$ at $4{ }^{\circ} \mathrm{C}$ to remove impurities and then flash frozen at $-80{ }^{\circ} \mathrm{C}$. To confirm sonication efficiencies, $100 \mu \mathrm{L}$ of sonicated chromatin was purified and resolved via electrophoresis to confirm 700-bp fragments. For IPs, $50 \mu \mathrm{g}$ of each chromatin preparation was diluted to $1 \mathrm{~mL}$ in dilution buffer [1\% Triton X-100 (Santa Cruz Biotech), 2 mM EDTA, $150 \mathrm{mM}$ sodium chloride (NaCl) (Sigma), $20 \mathrm{mM}$ Tris$\mathrm{HCl}, \mathrm{pH}$. 8.0]. Chromatin was precleared for $3 \mathrm{~h}$ at $4{ }^{\circ} \mathrm{C}$ with nutation with $20 \mu \mathrm{L}$ of washed [3× PBS buffer + BSA $(5 \mathrm{mg} / \mathrm{mL})$ (Sigma)] Magna ChIP Protein A $+\mathrm{G}$ (Millipore). Fifty $\mu \mathrm{L}(20 \%)$ of precleared chromatin was frozen for input control. Chromatin from nontransfected cells was incubated with $5 \mu \mathrm{g}$ of rabbit anti-H3K27me3 07-449 (Millipore) or $5 \mu \mathrm{g}$ of rabbit $\operatorname{IgG}$ (Cell Signaling 27295) at $4{ }^{\circ} \mathrm{C}$ for $12 \mathrm{~h}$ with nutation. Chromatin from dCas/sgRNA plasmid-transfected cells was incubated with $40 \mu \mathrm{L}$ of washed anti-FLAG M2 magnetic beads (M8823, Sigma) ( $3 \times$ with TBS $(50 \mathrm{mM}$ Tris $\mathrm{HCl}, 150 \mathrm{mM} \mathrm{NaCl}, \mathrm{pH} 7.4)$ or $5 \mu \mathrm{g}$ of rabbit IgG (Cell Signaling 27295) at $4{ }^{\circ} \mathrm{C}$ for $12 \mathrm{~h}$ with nutation. Chromatin-antiFLAG-bead complexes were washed three times with TBS buffer. Chromatin-antiH3K27me3 and chromatin-IgG samples were incubated with $20 \mu \mathrm{L}$ Magna ChIP Protein A $+\mathrm{G}$ beads for $3 \mathrm{~h}$ at $4{ }^{\circ} \mathrm{C}$ with nutation and then washed 6 times with 10 min rotating incubations with RIPA buffer [50 mM HEPES pH 7.6 (Thermo Fisher Scientific), $1 \mathrm{mM}$ EDTA, 0.7\% Sodium-Deoxycholate (Sigma), 1\% IGEPAL CA-630 (Sigma), $0.5 \mathrm{M} \mathrm{LICl}$ (Sigma)] and two times with 5 min rotating incubations with tris-EDTA pH 7.6 (Sigma). Washed chromatin-antibody-bead complexes were resuspended in $100 \mu \mathrm{L}$ of elution buffer [1\% SDS, $0.1 \mathrm{M}$ sodium bicarbonate (Sigma), $0.1 \mathrm{M} \mathrm{NaCl}$ ]. Fifty $\mu \mathrm{L}$ inputs were brought up to $100 \mu \mathrm{L}$ in elution buffer. IPs and inputs were nutated for $30 \mathrm{~min}$ at room temperature then incubated at $65{ }^{\circ} \mathrm{C}$ for $9 \mathrm{~h}$ to reverse cross-linking. Samples were treated for $30 \mathrm{~min}$ at $37^{\circ} \mathrm{C}$ with $10 \mu \mathrm{g}$ of RNase A and then for $2 \mathrm{~h}$ at $62{ }^{\circ} \mathrm{C}$ with $10 \mu \mathrm{g}$ of Proteinase K. DNA from IPs and inputs was purified with Genelute PCR Cleanup Kit (Sigma) and eluted in $50 \mu \mathrm{L}$ nuclease-free water.

\section{Real-Time Quantitative PCR of ChIP-Enriched DNA}

Real-time quantitative PCR reactions ( $15 \mu \mathrm{L}$ each) contained SYBR Green master mix, $2 \mu \mathrm{L}$ of immunoprecipitated (IP), IgG-IP, or input template DNA, and 2.25 pmol of primers. Input $\mathrm{Cp}$ values were adjusted by subtracting $\log _{2}(20)$ from each input $\mathrm{Cp}$, as $50 \mu \mathrm{L}$ was taken from $1 \mathrm{~mL}$ total chromatin or 1/20. \% IP DNA bound was calculated as $100 \times$ $2^{[\mathrm{Ct} \text { input-Ct IP] }} . \%$ IgG-IP bound $\left(100 \times 2^{[\mathrm{Ct} \text { input-Ct IgG-IP] }}\right.$ was subtracted from $\%$ IP DNA bound to calculate \% IP enrichment (minus IgG mock IP) for H3K27me3 mapping. For dCas9 enrichment, \% IP enrichment (minus IgG mock IP) at site GAPDH was subtracted from \% IP enrichment (minus IgG mock IP) at Site 1 to calculate \% IP enrichment (minus background). 
Primer sequences for site 1 were as follows:

$5^{\prime}$-cgaccctgcataagcttgcc (forward);

$5^{\prime}$-ccgcgtacgtgatgttcacc (reverse).

Primer sequences for site 2 were as follows:

$5^{\prime}$-gcgccegcgaacgacattta (forward);

$5^{\prime}$-gagatgtgacgaacgtgtac (reverse).

Primer sequences for site 3 were as follows:

$5^{\prime}$-gcgcccgcgaacgacattta (forward);

$5^{\prime}$-gagatgtgacgaacgtgtac (reverse).

Primer sequences for site 4 were as follows:

$5^{\prime}$-ttgtaccagagtcctttgatcg (forward);

$5^{\prime}$-ccgtgatggaatggaacaac (reverse).

Primer sequences for GAPDH were as follows:

$5^{\prime}$-tactagcggttttacgggcg (forward);

$5^{\prime}$-tcgaacaggaggagcagagagcga (reverse).

Statistical Analyses-For analyses of ChIP-qPCR Assay data, standard deviations were calculated for $n=3$ replicate IPs from single chromatin preps. The differences of means for Luc14/ GAL4EED cells and Luc14/GAL4EED + dox cells were calculated using the two sample, one-tailed Student's $t$ test. For $p<0.05$, confidence was $95 \%$ for 2 degrees of freedom and a test statistic of $t_{(0.05,2)}=2.920$. For $p<0.01$, confidence was $99 \%$ for 2 degrees of freedom and a test statistic of $t_{(0.01,2)}=6.965$.

\section{siRNA Transfections}

At time $0 \mathrm{~h}$, puromycin (puro) was removed and GAL4EED cells were induced with doxycycline (dox, Santa Cruz Biotechnology) at $1 \mu \mathrm{g} / \mathrm{mL}$. At $96 \mathrm{~h}$, dox was removed and media with puro was used. Cells were seeded in 12-well plates such that at $96 \mathrm{~h}$, cells were at $50 \%$ confluency. One well was collected for Luciferase assay (see above). The remaining wells were used for lipid-mediated transfection with $2.5 \mu \mathrm{L}$ of $20 \mu \mathrm{M}$ anti-SUZ12 siRNA duplex (Dharmacon)/well and $1.5 \mu \mathrm{L}$ Oligofectamine (Life Technologies) per manufacturer's protocol. siRNA sequence used was as follows: ${ }^{16}$

Sense: $5^{\prime}$ A.A.G.C.U.G.U.U.A.C.C.A.A.G.C.U.C.C.G.U.-G.U.U 3';

Antisense: $5^{\prime}$ C.A.C.G.G.A.G.C.U.U.G.G.U.A.A.C.A.G.-C.U.U.U.U 3' .

Mock transfected cells (water used in place of siRNA duplex) were used as a control. At 144 $\mathrm{h}$, siRNA and mock transfections were repeated. At $264 \mathrm{~h}$, siRNA and mock transfected cells were transfected with Cas9/sg034 (three experimental replicates) (see above). At $336 \mathrm{~h}$ cells were collected to determine luciferase expression, transfection efficiency, and editing efficiency (see above). 


\title{
Supplementary Material
}

Refer to Web version on PubMed Central for supplementary material.

\section{Acknowledgments}

The authors thank J. Steel (DNASU) for DNA sequencing services and the 2014 Cold Spring Harbor Synthetic Biology Summer Course for supporting our development of this study. The authors thank F. Ceroni, J. Eisenberg, C. Barrett, D. Nyer, D. Vargas, and K. Timms for critical review of the manuscript. KAH is supported by the NIH NCI (K01CA188164) and the NSF/Synberc (EEC 0540879). RMD is supported by the ARCS Foundation and NSF CBET (1404084).

\author{
ABBREVIATIONS \\ CRISPR clustered regularly interspaced palindromic repeats \\ PRC Polycomb Repressive Complex \\ sgRNA short guide RNA \\ INDEL insertion and deletion
}

\section{REFERENCES}

1. Ran FA, Hsu PD, Lin CY, Gootenberg JS, Konermann S, Trevino AE, Scott Da, Inoue A, Matoba S, Zhang Y, Zhang F. Double nicking by RNA-guided CRISPR cas9 for enhanced genome editing specificity. Cell. 2013; 154:1380-1389. [PubMed: 23992846]

2. Hsu PD, Lander ES, Zhang F, Sciences C, Biology C. Development and applications of CRISPRCas9 for genome engineering. Cell. 2014; 157:1262-1278. [PubMed: 24906146]

3. Sánchez-Rivera FJ, Jacks T. Applications of the CRISPR-Cas9 system in cancer biology. Nat. Rev. Cancer. 2015; 15:387-395. [PubMed: 26040603]

4. Cong L, Ran FA, Cox D, Lin S, Barretto R, Habib N, Hsu PD, Wu X, Jiang W, Marraffini La, Zhang F. Multiplex genome engineering using CRISPR/Cas systems. Science. 2013; 339:819-823. [PubMed: 23287718]

5. Tiwari VK, Cope L, McGarvey KM, Ohm JE, Baylin SB. A novel 6C assay uncovers Polycombmediated higher order chromatin conformations. Genome Res. 2008; 18:1171-1179. [PubMed: 18502945]

6. Bell O, Tiwari VK, Thomä NH, Schübeler D. Determinants and dynamics of genome accessibility. Nat. Rev. Genet. 2011; 12:554-564. [PubMed: 21747402]

7. Aoto T, Saitoh N, Sakamoto Y, Watanabe S, Nakao M. Polycomb group protein-associated chromatin is reproduced in post-mitotic G1 phase and is required for S phase progression. J. Biol. Chem. 2008; 283:18905-18915. [PubMed: 18453536]

8. Wu X, Scott Da, Kriz AJ, Chiu AC, Hsu PD, Dadon DB, Cheng AW, Trevino AE, Konermann S, Chen S, Jaenisch R, Zhang F, Sharp Pa. Genome-wide binding of the CRISPR endonuclease Cas9 in mammalian cells. Nat. Biotechnol. 2014; 32:670-676. [PubMed: 24752079]

9. Hsu PD, Scott Da, Weinstein Ja, Ran FA, Konermann S, Agarwala V, Li Y, Fine EJ, Wu X, Shalem O, Cradick TJ, Marraffini La, Bao G, Zhang F. DNA targeting specificity of RNA-guided Cas9 nucleases. Nat. Biotechnol. 2013; 31:827-832. [PubMed: 23873081]

10. Bultmann S, Morbitzer R, Schmidt CS, Thanisch K, Spada F, Elsaesser J, Lahaye T, Leonhardt H. Targeted transcriptional activation of silent oct 4 pluripotency gene by combining designer TALEs and inhibition of epigenetic modifiers. Nucleic Acids Res. 2012; 40:5368-5377. [PubMed: 22387464] 
11. Valton J, Dupuy A, Daboussi F, Thomas S, Maréchal A, Macmaster R, Melliand K, Juillerat A, Duchateau P. Overcoming transcription activator-like effector (TALE) DNA binding domain sensitivity to cytosine methylation. J. Biol. Chem. 2012; 287:38427-38432. [PubMed: 23019344]

12. Chen X, Rinsma M, Janssen JM, Liu J, Maggio I, Gonçalves MAFV. Probing the impact of chromatin conformation on genome editing tools. Nucleic Acids Res. 2016; 44:6482-6492. [PubMed: 27280977]

13. Kuscu C, Arslan S, Singh R, Thorpe J, Adli M. Genome-wide analysis reveals characteristics of off-target sites bound by the Cas9 endonuclease. Nat. Biotechnol. 2014; 32:677-683. [PubMed: 24837660]

14. Singh R, Kuscu C, Quinlan A, Qi Y, Adli M. Cas9-chromatin binding information enables more accurate CRISPR off-target prediction. Nucleic Acids Res. 2015; 43:e118. [PubMed: 26032770]

15. Perez-Pinera P, Kocak DD, Vockley CM, Adler AF, Kabadi M, Polstein LR, Thakore PI, Glass KA, Ousterout DG, Leong KW, Guilak F, Crawford GE, Reddy TE, Gersbach CA. RNA-guided gene activation by CRISPR-Cas9-based transcription factors. Nat. Methods. 2013; 10:973-976. [PubMed: 23892895]

16. Hansen KH, Bracken AP, Pasini D, Dietrich N, Gehani SS, Monrad A, Rappsilber J, Lerdrup M, Helin K. A model for transmission of the H3K27me3 epigenetic mark. Nat. Cell Biol. 2008; 10:1291-1300. [PubMed: 18931660]

17. Simon JA, Kingston RE. Occupying chromatin: Polycomb mechanisms for getting to genomic targets, stopping transcriptional traffic, and staying put. Mol. Cell. 2013; 49:808-824. [PubMed: 23473600]

18. Bernstein BE, Mikkelsen TS, Xie X, Kamal M, Huebert DJ, Cuff J, Fry B, Meissner A, Wernig M, Plath K, Jaenisch R, Wagschal A, Feil R, Schreiber SL, Lander ES. A bivalent chromatin structure marks key developmental genes in embryonic stem cells. Cell. 2006; 125:315-326. [PubMed: 16630819]

19. Aoki R, Chiba T, Miyagi S, Negishi M, Konuma T, Taniguchi H, Ogawa M, Yokosuka O, Iwama A. The polycomb group gene product Ezh2 regulates proliferation and differentiation of murine hepatic stem/progenitor cells. J. Hepatol. 2010; 52:854-863. [PubMed: 20395008]

20. Xie R, Everett LJ, Lim H-W, Patel NA, Schug J, Kroon E, Kelly OG, Wang A, D’Amour KA, Robins AJ, Won K-J, Kaestner KH, Sander M. Dynamic chromatin remodeling mediated by polycomb proteins orchestrates pancreatic differentiation of human embryonic stem cells. Cell stem cell. 2013; 12:224-237. [PubMed: 23318056]

21. Squazzo SL, O’Geen H, Komashko VM, Krig SR, Jin VX, Jang S, Margueron R, Reinberg D, Green R, Farnham PJ. Suz12 binds to silenced regions of the genome in a cell-type-specific manner. Genome Res. 2006; 16:890-900. [PubMed: 16751344]

22. Sparmann A, Van Lohuizen M. Polycomb silencers control cell fate, development and cancer. Nat. Rev. Cancer. 2006; 6:846-856. [PubMed: 17060944]

23. Haynes KA, Silver PA. Synthetic reversal of epigenetic silencing. J. Biol. Chem. 2011; 286:2717627182. [PubMed: 21669865]

24. Nakagawa Y, Sakuma T, Sakamoto T, Ohmuraya M, Nakagata N, Yamamoto T. Production of knockout mice by DNA microinjection of various CRISPR/Cas9 vectors into freeze-thawed fertilized oocytes. BMC Biotechnol. 2015; 15(1):33. [PubMed: 25997509]

25. Pattanayak V, Lin S, Guilinger JP, Ma E, Doudna JA, Liu DR. High-throughput profiling of offtarget DNA cleavage reveals RNA-programmed Cas9 nuclease specificity. Nat. Biotechnol. 2013; 31:839-843. [PubMed: 23934178]

26. Horlbeck MA, Witkowsky LB, Guglielmi B, Replogle JM, Gilbert LA, Villalta JE, Torigoe SE, Tjian R, Weissman JS. Nucleosomes impede Cas9 access to DNA in vivo and in vitro. eLife. 2016; 5:e12677. [PubMed: 26987018]

27. Isaac RS, Jiang F, Doudna JA, Lim WA, Narlikar GJ, Almeida R. Nucleosome breathing and remodeling constrain CRISPR-Cas9 function. eLife. 2016; 5:e13450. [PubMed: 27130520]

28. Cavalli G, Paro R. Epigenetic inheritance of active chromatin after removal of the main transactivator. Science. 1999; 286:955-958. [PubMed: 10542150] 
29. Tan J, Yang X, Zhuang L, Jiang X, Chen W, Lee PL, Karuturi RKM, Tan PBO, Liu ET, Yu Q. Pharmacologic disruption of Polycomb-repressive complex 2-mediated gene repression selectively induces apoptosis in cancer cells. Genes Dev. 2007; 21:1050-1063. [PubMed: 17437993]

30. Kanduri M, Sander B, Ntoufa S, Papakonstantinou N, Sutton L, Stamatopoulos K, Kanduri C, Rosenquist R. A key role for EZH2 in epigenetic silencing of HOX genes in mantle cell lymphoma. Epigenetics. 2013; 8:1280-1288. [PubMed: 24107828]

31. Katoh K, Standley DM. MAFFT multiple sequence alignment software version 7: improvements in performance and usability. Mol. Biol. Evol. 2013; 30:772-780. [PubMed: 23329690] 
a

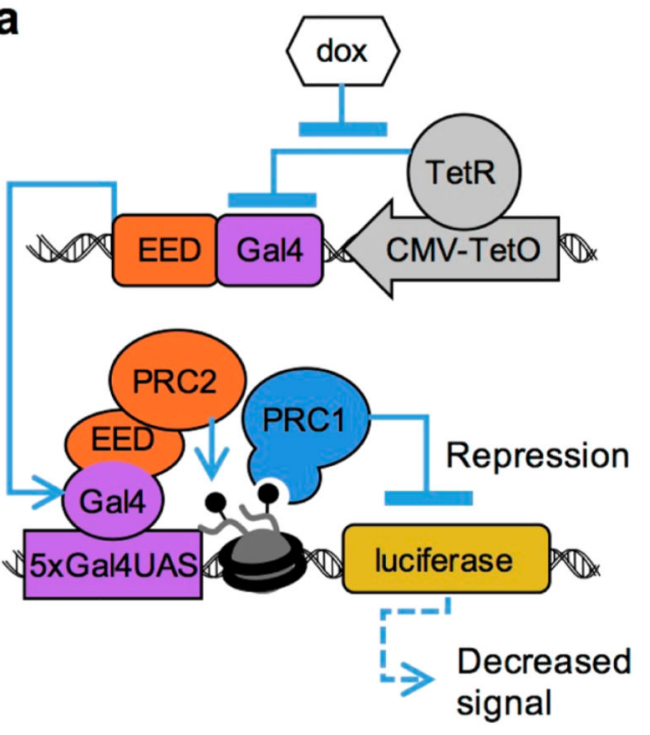

b

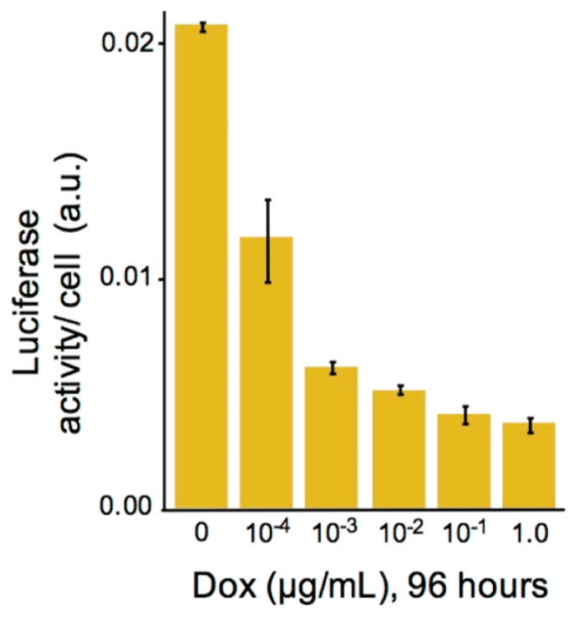

C

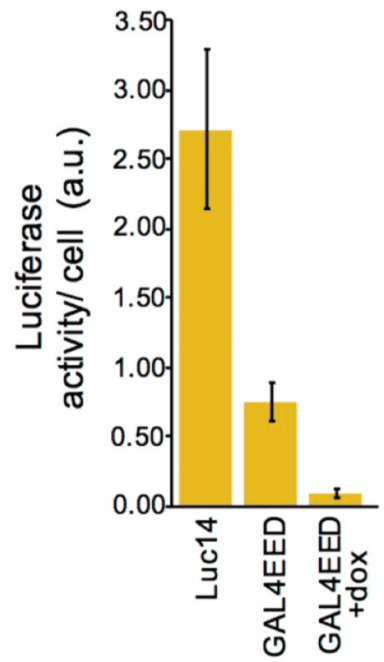

Figure 1.

A closed chromatin state at luciferase is regulated by doxycycline (dox) in GAL4EED cells.

(a) The GAL4EED circuit diagram illustrates how dox regulates the expression of the Gal4EED fusion protein, which mediates accumulation of Polycomb Repressive Complex 1 (PRC1) and closed chromatin at the luciferase reporter. (b) A repressed expression state at luciferase is stimulated by dox in GAL4EED cells. (c) Comparison of luciferase expression in cells that lack a Ga14EED gene (Luc14), and GAL4EED cells before and after treatment with dox. a.u.: arbitrary units from luminescence readings. Error bars indicate s.d. for $n=3$ technical replicates. 
a

Transfect cells

PCR around cut site

SURVEYOR Assay

DNA fragment analysis with Cas9/sgRNA
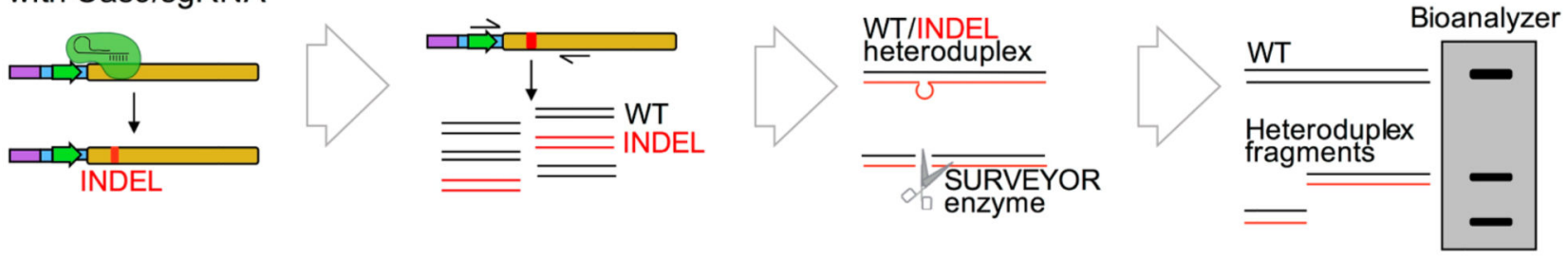

b
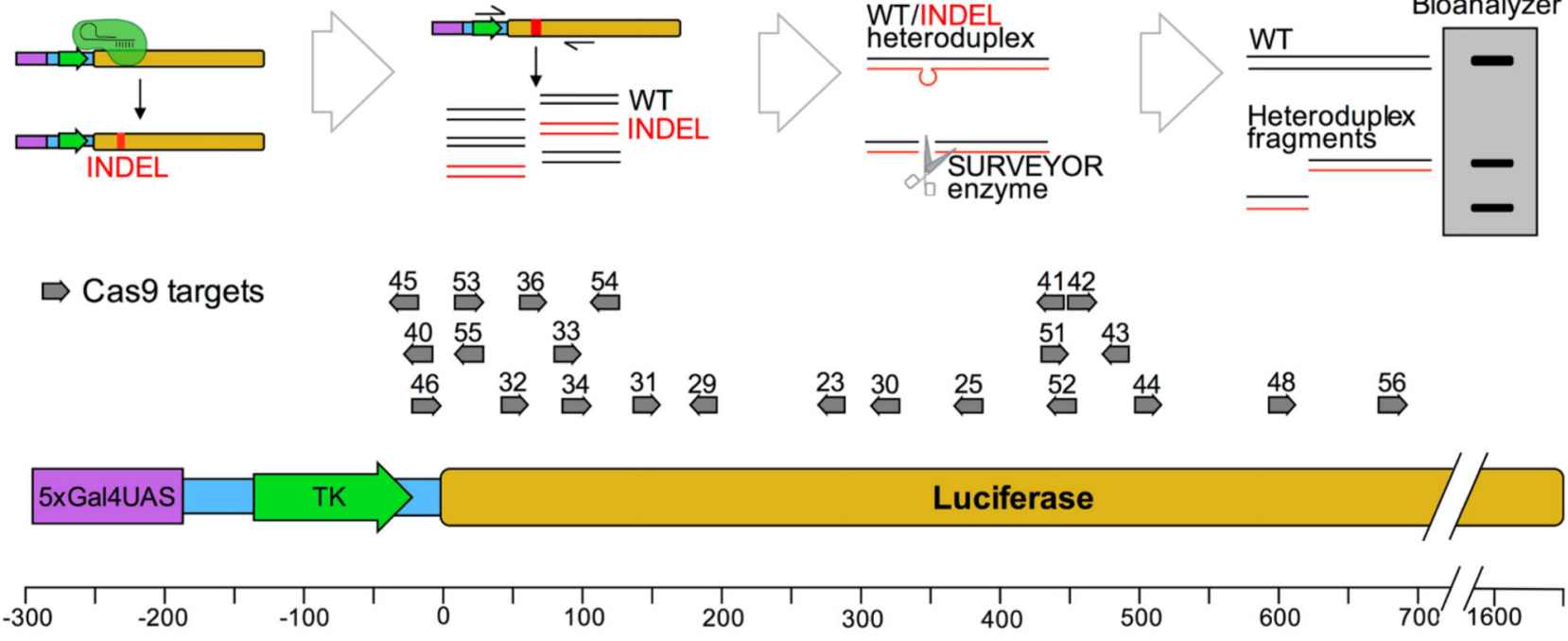

Distance from translational start site (bp)

C

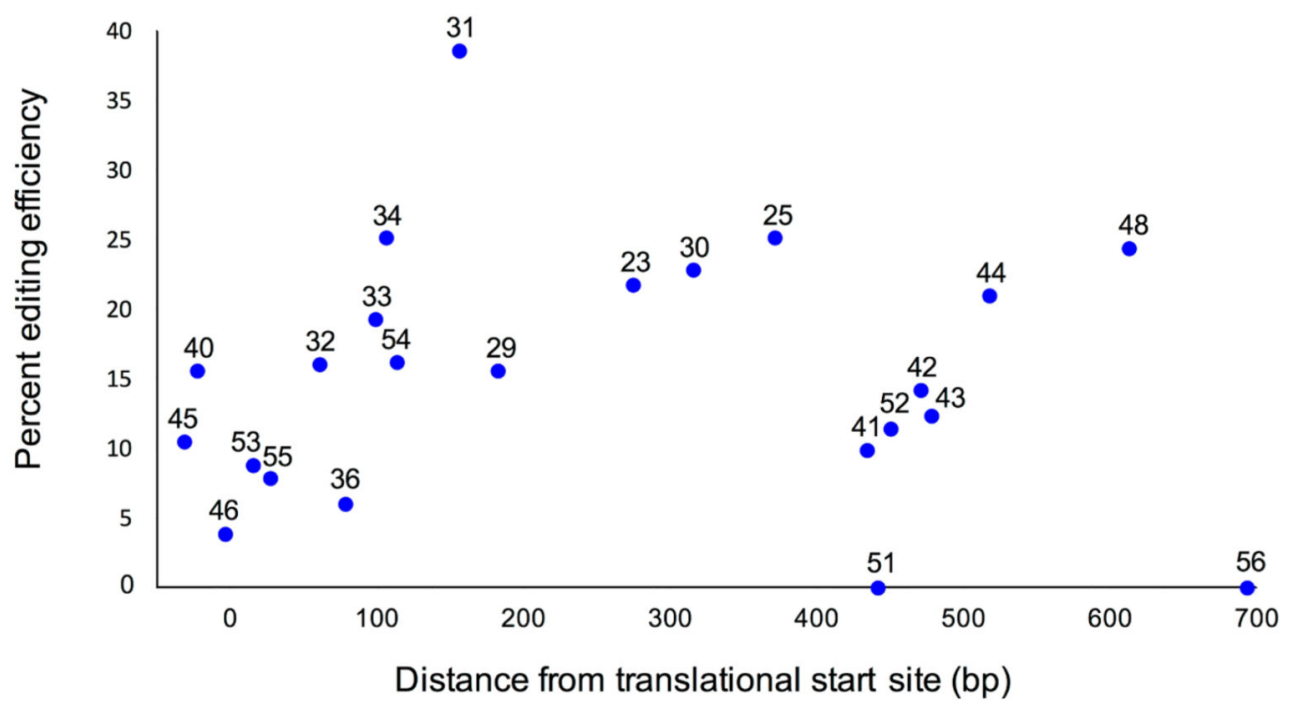

Figure 2.

Editing efficiency at different Cas9/sgRNA target sites detected by SURVEYOR assays. (a) Diagram of the SURVEYOR assay. INDELS: Insertions and deletions; WT: wildtype (b) Map of all sgRNAs tested in this study. Arrows show Cas9/sgRNA binding sites. (c) SURVEYOR results from a screen to identify sgRNAs with detectable editing rates at the UAS-TK-luciferase reporter in Luc14 cells. 
a

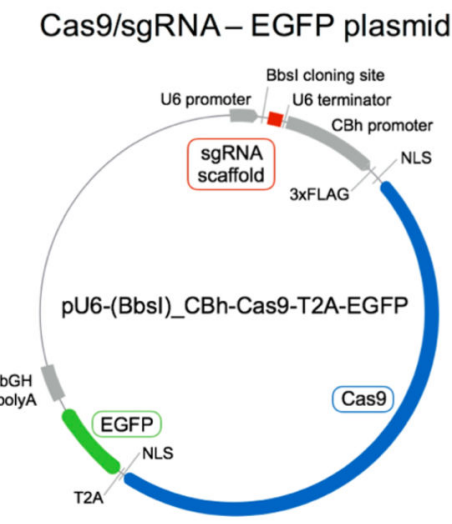

b

\begin{tabular}{l|r|r|r|} 
& \multicolumn{1}{c}{ Luc14 } & GAL4EED & GAL4EED +dox \\
\hline sg046 & $51.1 \pm 7.6$ & $32.4 \pm 0.2$ & $36.9 \pm 1.7$ \\
sg055 & $30.1 \pm 4.1$ & $29.4 \pm 1.6$ & $38.2 \pm 2.6$ \\
sg032 & $51.1 \pm 7.0$ & $33.0 \pm 1.3$ & $38.0 \pm 0.2$ \\
sg034 & $32.5 \pm 3.6$ & $33.2 \pm 2.5$ & $23.5 \pm 2.1$ \\
sg054 & $32.3 \pm 3.9$ & $12.1 \pm 1.4$ & $12.3 \pm 0.8$ \\
sg031 & $55.7 \pm 3.2$ & $32.0 \pm 1.8$ & $31.9 \pm 2.0$ \\
sg025 & $50.8 \pm 6.1$ & $31.8 \pm 1.1$ & $34.1 \pm 0.8$ \\
sg044 & $37.1 \pm 3.0$ & $30.5 \pm 1.3$ & $34.3 \pm 2.0$ \\
sg048 & $49.5 \pm 2.8$ & $35.3 \pm 2.6$ & $28.3 \pm 3.2$
\end{tabular}

C

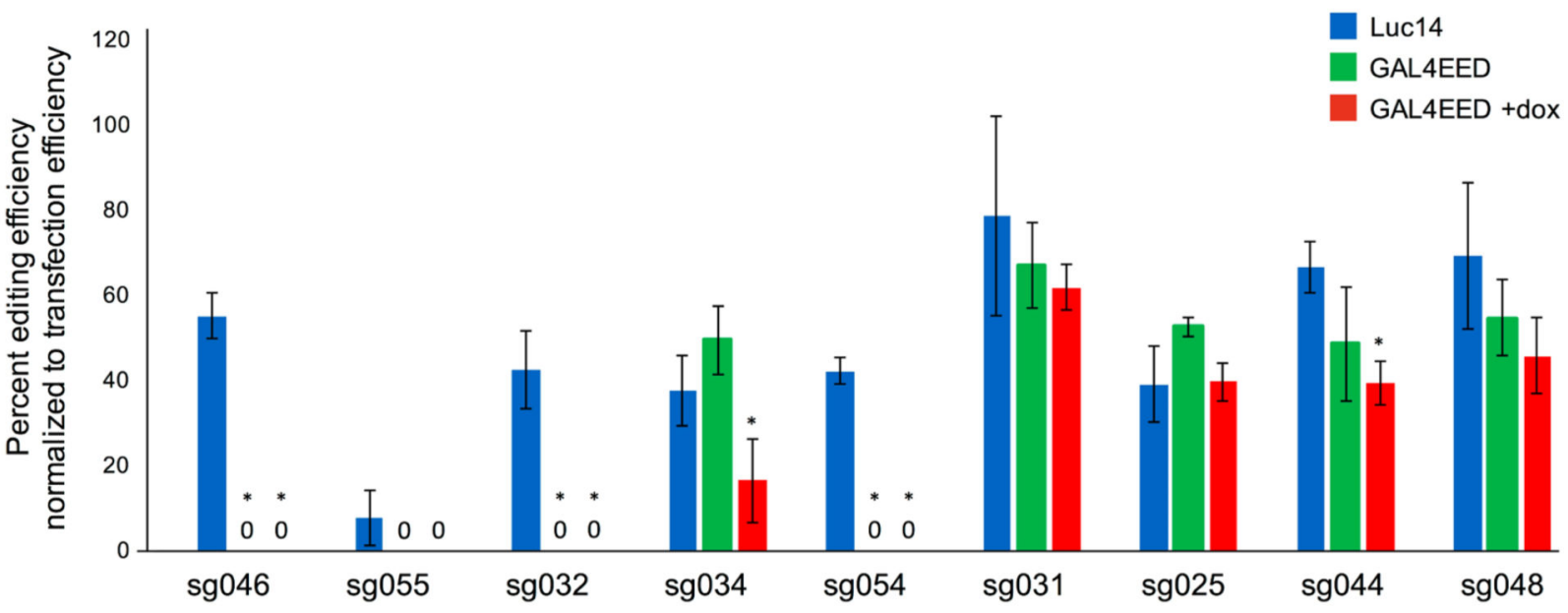

Cas9/sgRNA target site

d

$\square$ Editing reduced at partially and fully silenced site

$\rightarrow$ Editing reduced at fully silenced site

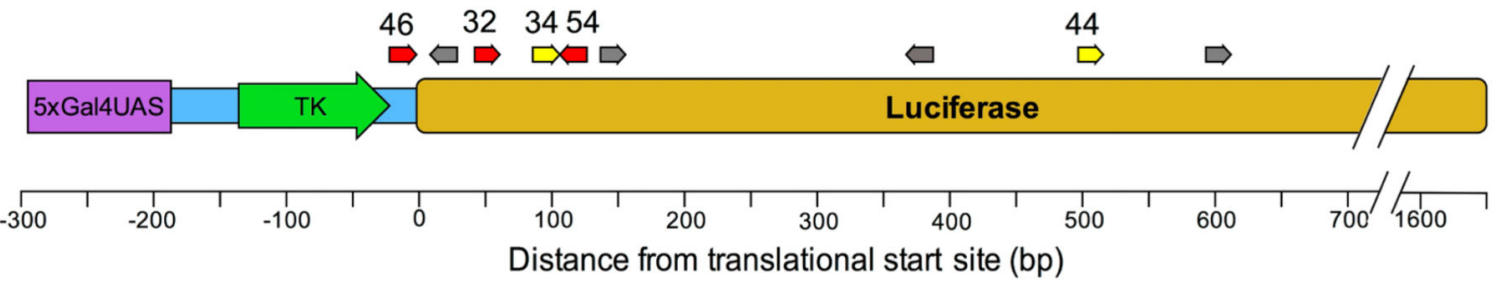

Figure 3.

Cas9 editing efficiencies at target sites in unsilenced, partially silenced, and fully silenced chromatin states. (a) A map of the Cas9/sgRNA-expressing plasmid. Cas9 and EGFP expression are both driven by the CBh promoter. The T2A signal allows EGFP to be translated as a separate peptide to avoid interference of Cas9 function. (b) Table of average frequencies of EGFP-expressing cells (transfection efficiencies) as determined by flow cytometry of triplicate samples for transfected Luc14, GAL4EED, and GAL4EED cells treated with doxycycline. (c) Mean editing frequencies normalized to transfection efficiency 
in Luc14, GAL4EED, or GAL4EED + dox cells for Cas9 targeted to sites $\operatorname{sg} 046$, $\operatorname{sg} 055$, sg032, sg034, sg054, sg031, sg025, sg044, and sg048. *Indicates significantly reduced editing efficiencies at fully silenced chromatin compared to unsilenced chromatin $(p<0.025$ for 3 biological replicates). Editing frequencies for target sites $\mathrm{sg} 046, \mathrm{sg} 055, \mathrm{sg} 032$, and $\operatorname{sg} 054$ for both GAL4EED or GAL4EED + dox cell types were below detection limits. Error bars indicate s.d. for $n=3$ biological replicates. (d) Summary of the data in (c). Cas9 target sites $\mathrm{sg} 046, \mathrm{sg} 032$, and $\mathrm{sg} 054$ show a reduction in editing efficiency in both the partially and fully silenced states compared to the unsilenced states (red arrows). Cas 9 target sites sg034 and $\mathrm{sg} 044$ show a reduction in editing efficiency in the fully silence states compared to the unsilenced states (yellow arrows). 
GGCTATGAAGAGAT

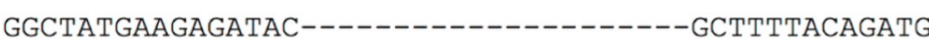
GGCTATGAAGAGATACGGCTATGAAGAGATGGCTATGAAGAGATACGCCCTGG------------TGCTTTTACAGATG GGCTATGAAGAGATACGCCCTGG-----------TTGCTaTTACAGATG GGCTATGAAGAGATACGCCCTGGT-----------TTGCTTTTACAGATG GGCTATGAAGAGA-----------TCCTGGAACAATTGCTTTTACAGATG GGCTATGAAGAGATACGCCCT--------GAACAATTGCTTTTACAGATG GGCTATGAAGAGATAC--------TCCTGGAACAATTGCTTTTACAGATG GGCTATGAAGAGATACGCCCTGGTTCCTG-------TGCTTTTACAGATG GGCTATGAAGAGATACGC-------CCTGGAACAATTGCTTTTACAGATG GGCTATGAAGAGATACGC------TCCTGGAACAATTGCTTTTACAGATG GGCTATGAAGAGATACG-------gTCCTGGAACAATTGCTTTTACAGATG GGCTATGAAGAGATACGCC-----TCCTGGAACAATTGCTTTTACAGATG GGCTATGAAGAGATACGCCCTGGT-----GAACAATTGCTTTTACAGATG GGCTATGAAGAGATACGCCCTGG----TGGAACAATTGCTTTTACAGATG GGCTATGAAGAGATACGCCC---TTCCTGGAACAATTGCTTTTACAGATG GGCTATGAAGAGATACGCCCTG--TCCTGGAACAATTGCTTTTACAGATG GGCTATGAAGAGATACGCCCTGG-TCCTGGAACAATTGCTTTTACAGATG GGCTATGAAGAGATACGCCCTGGTTCCTGGAACAATTGCTTTTACAGATG GGCTATGAAGAGATACGCCCTGGTnTCCTGGAACAATTGCTTTTACAGATG GGCTATGAAGAGATACGCCCTGgtGTTCCTGGAACAATTGCTTTTACAGATG GGCTATGAAGAGATACGCCCTGGTataTCCTGGAACAATTGCTTTTACAGATG GGCTATGAAGAGATACGCCCTGGT [ 69] TCCTGGAACAATTGCTTTTACAGATG GGCTATGAAGAGATACGCCCTG [ [99] GTTCCTGGAACAATTGCTTTTACAGATG GGCTATGAAGAGATACGCCCTG [205] GTTCCTGGAACAATTGCTTTTACAGATG ㅇ GGCTATGAAGAGATACGCCCTGGTTCCTGGAACAATTGCcTtTACAGATG GGCTATGAAGAGATACGCCC.GGTTCCTGGAACAATTGCTTTTACAGATG

$\begin{array}{ll}\text { Target site } & \text { - Deletion } \\ \boldsymbol{\nabla} \text { Cleavage site } & \underline{n} \text { Insertion } \\ \text { PAM } & \mathbf{n} \text { Substitution }\end{array}$

b

Figure 4.
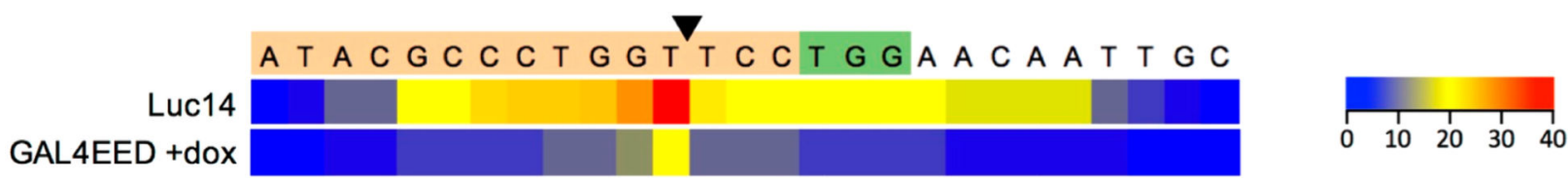

Frequencies of mutations in genomic DNA from Cas9/sg034-treated Luc14 or GAL4EED + dox cells. (a) Each row shows the mutated sequence aligned to the wild type sequence (WT). Bar graphs show the percentage of library clones that correspond to the sequence in the same row on the left. (b) The heat map shows the number of times each nucleotide position was affected by a deletion that arose from nonhomologous end joining (NHEJ) repair. 
a
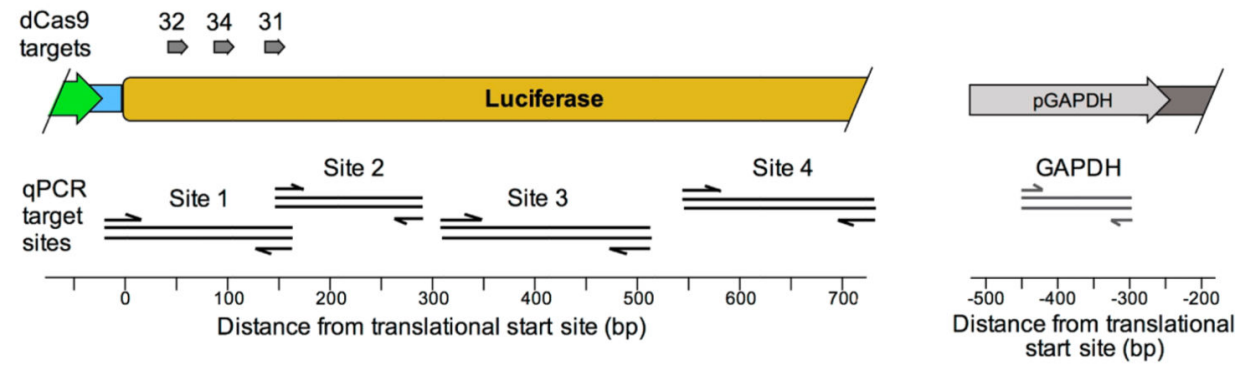

b

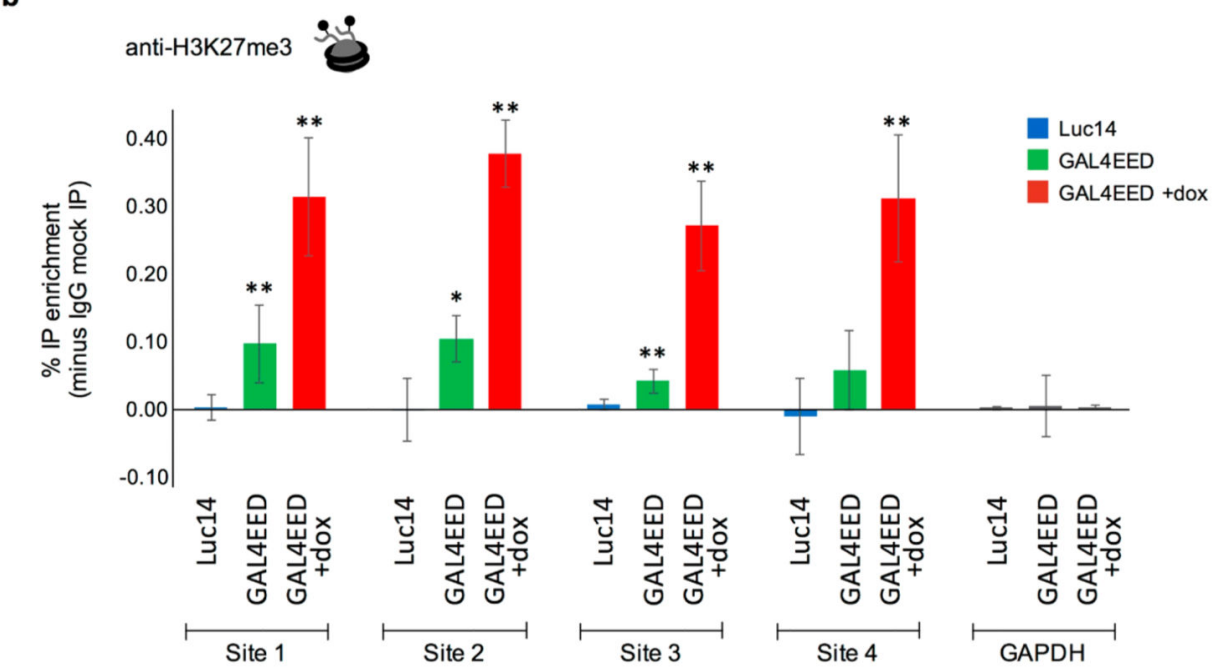

C
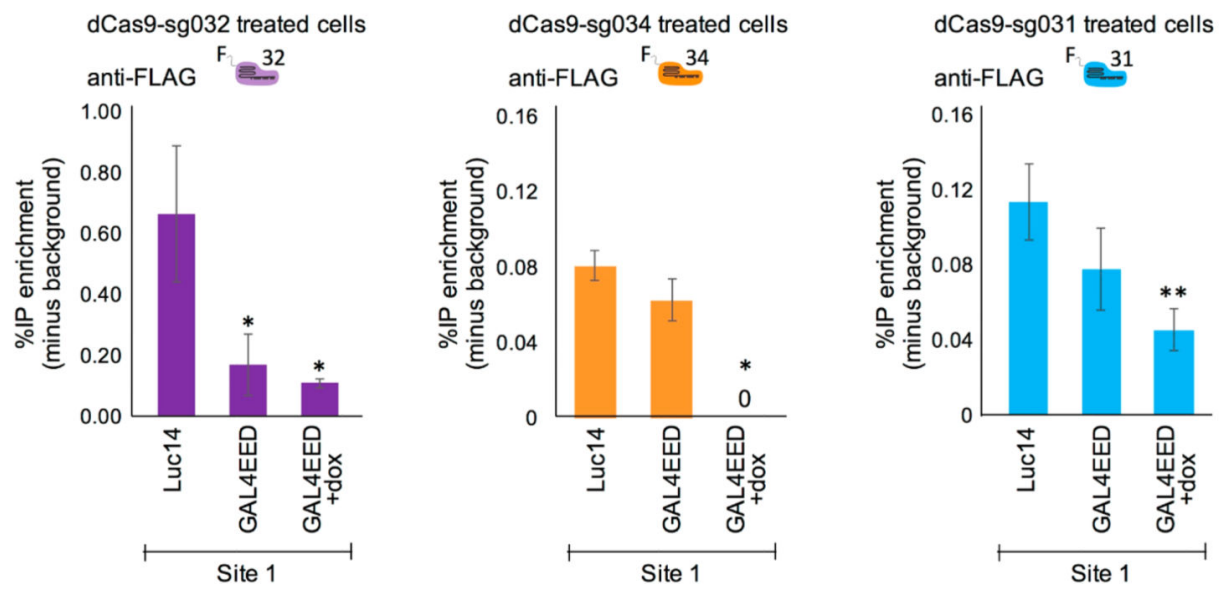

Figure 5.

Chromatin mapping data show differential enrichment of $\mathrm{H} 3 \mathrm{~K} 27 \mathrm{me} 3$ and dCas 9 at luciferase in the open, partially closed, and closed chromatin states. (a) Cross-linked, sheared chromatin was prepared from Luc14 (unsilenced), GAL4EED (partially silenced), or GAL4EED + dox (fully silenced) cells. An anti-H3K27me3 antibody was used to immunoprecipitate (IP) chromatin from untreated cells. An anti-FLAG antibody was used to IP chromatin from dCas9_gRNA-transfected cells. Quantitative PCR (qPCR) was used to measure IP'ed DNA. Primers (described in Methods) and amplicon sizes are shown in the 
illustrated maps. A primer pair located at the constitutively active GAPDH promoter was used as a negative control to determine off-target binding. (b) Mean H3K27me3 enrichments for Luc14 (unsilenced), GAL4EED (partially silenced), and GAL4EED + dox (fully silenced) cells at four sites spanning the Cas9/sgRNA target sites. Enrichment is shown as percentages of input minus IgG mock IP. (c) Enrichments of IP DNA for dCas9 are shown for three gRNA target sites, $\operatorname{sg} 032, \operatorname{sg} 034$, and $\operatorname{sg} 031$ in three chromatin states, unsilenced, partially silenced, and fully silenced. Enrichments are shown as percentages of input minus background (IgG mock IP and GAPDH) (see Methods). In (b) and (c), error bars indicate s.d. for $n=3$ replicate IPs from a single chromatin preparation. A one-tailed $t$ test was done to compare Gal4EED or Gal4EED + dox to Luc14 $\left(* p<0.5,{ }^{* *} p<0.01\right)$. 
a

b
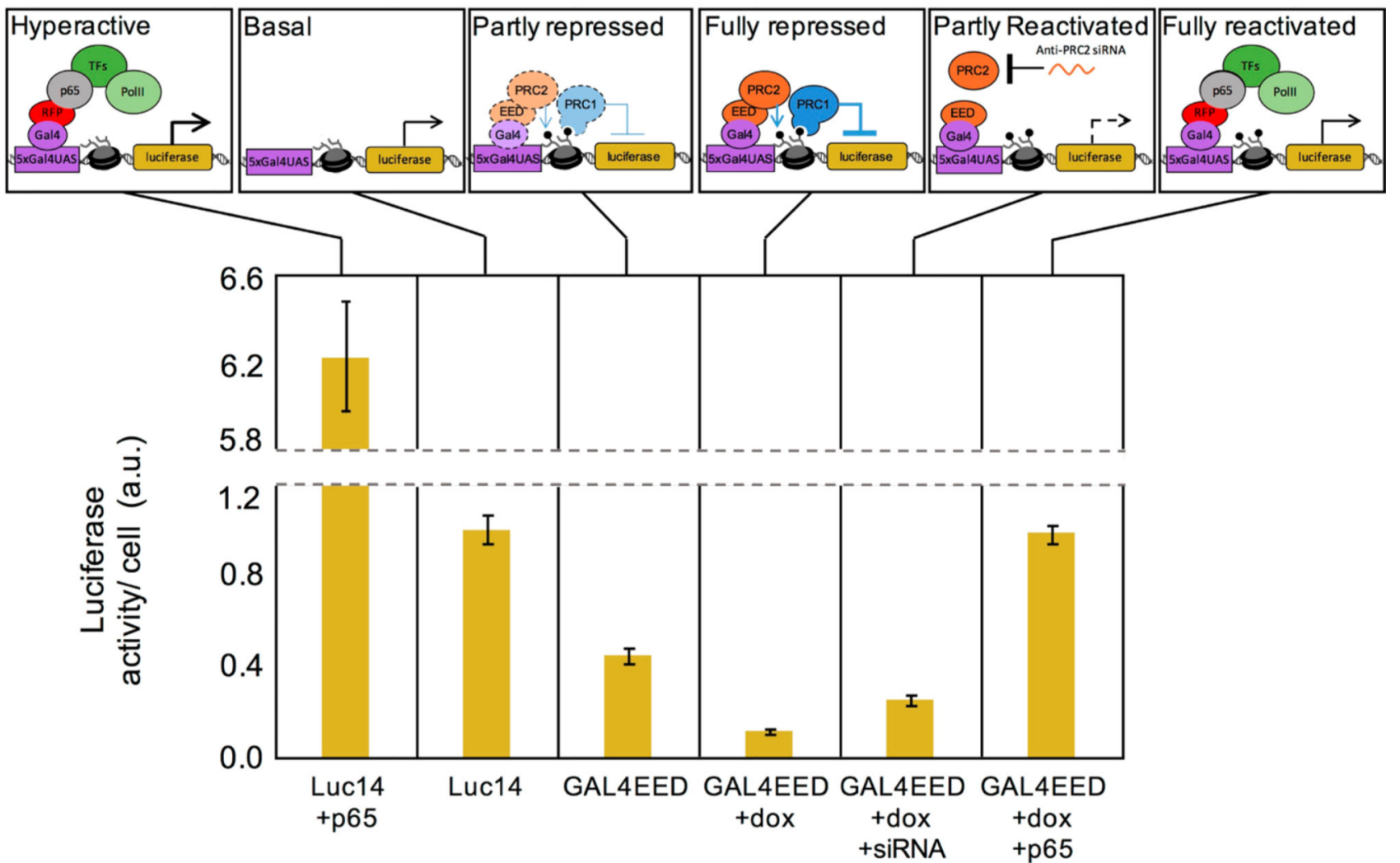

C

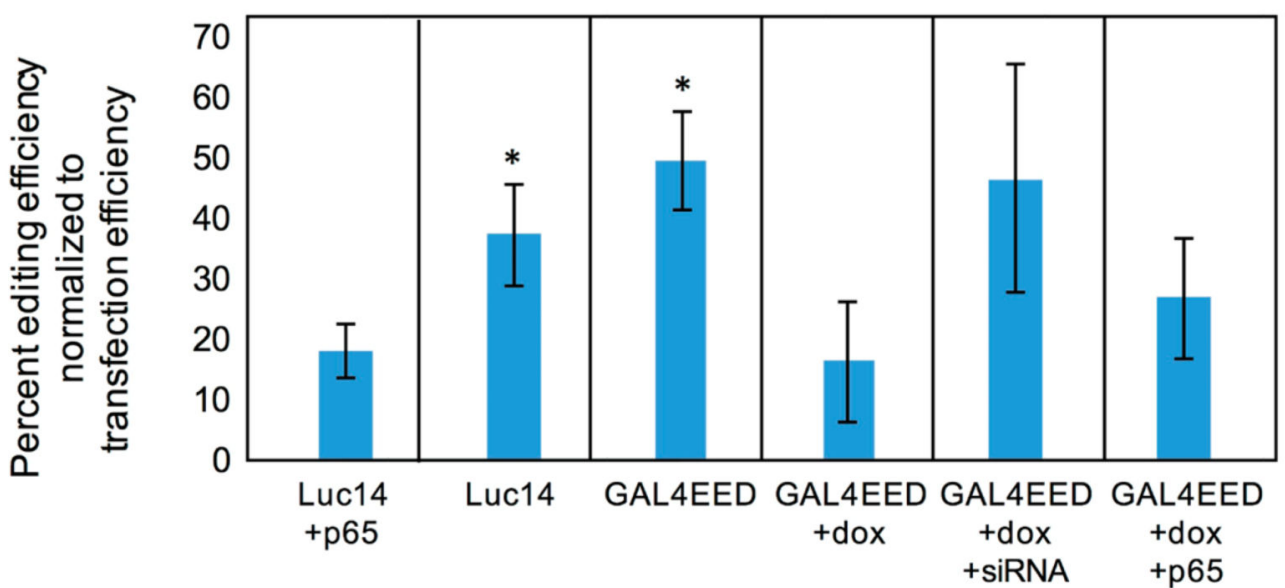

Figure 6.

Dynamic regulatory states impact Cas9-mediated editing at the luciferase transgene. (a) Illustration of the luciferase transgene in the basal expression state and in different, artificially regulated states. (b) Background-subtracted Luciferase expression levels per cell were measured $96 \mathrm{~h}$ after dox treatment (GAL4EED + dox), immediately before transfection with Gal4-p65 plasmid DNA (+p65), or mock-transfection (vehicle only). Luciferase expression was measured in siRNA-treated cells $336 \mathrm{~h}$ after transfection. a.u.: arbitrary units. (c) Editing efficiency for Cas9/sg034 was determined by SURVEYOR assays. Editing was reduced in the hyperactive expression state (Luc14 + p65) compared to the Luc14 basal 
state $(* p=0.018)$ and the GAL4EED partially repressed state $(* p=0.004)$. Reversal of the closed state via siRNA treatment (GAL4EED + dox + siRNA) was accompanied by an increase in luciferase expression and editing efficiency $(p=0.045)$ compared to the fully repressed state. Editing efficiencies for Luc14, GAL4EED, and GAL4EED + dox shown here are the same data shown in Figure 3c. 